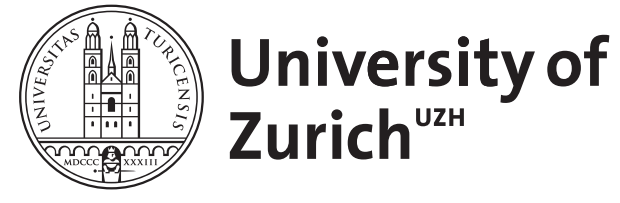

\title{
Sauerbruch, Ferdinand
}

\author{
Mörgeli, C
}

DOI: https://doi.org/10.1001/jama.1964.03070230082040

Posted at the Zurich Open Repository and Archive, University of Zurich ZORA URL: https://doi.org/10.5167/uzh-41348

Book Section

Originally published at:

Mörgeli, C (2011). Sauerbruch, Ferdinand. In: Jorio, M. Historisches Lexikon der Schweiz. Basel: Schwabe, 797.

DOI: https://doi.org/10.1001/jama.1964.03070230082040 


\section{Sauerbruch, Ferdinand}

* 3.7.1875 Barmen (heute Stadtteil von Wuppertal),† 2.7.1951 Berlin, prot., Deutscher. Sohn des Ferdinand, kaufmänn.-techn. Angestellter einer Tuchweberei, und der Helene geb.

Hammerschmidt. $\infty$ 1) 1908 Adeline Schulz, 2) 1939 Margot Grossmann. 1902 Dr. med. in Leipzig, 1903 Assistent und 1905 PD in Breslau, 1905 Asssistenzarzt, 1906 Oberarzt in Greifswald, 1908 ao. Prof. in Marburg. 1910-18 o. Prof. und Direktor der chirurg. Klinik am Kantonsspital Zürich, Pionier der Lungenchirurgie, oft in den Sanatorien von Davos tätig, 1915 Konflikt mit seinen Schweizer Assistenten nach Einforderung einer deutschnationalen Gesinnung. Ab 1918 o. Prof. in München, 1927-49 an der Charité in Berlin. S. war der einflussreichste Chirurg Deutschlands, der unter dem Nationalsozialismus seine Karriere unbeirrt fortführte und zu einer internat.

Vorzeigefigur wurde. Er beteiligte sich auch an der Vorbereitung der schweiz. Ärztemissionen an die Ostfront (1941-43).

\section{Literatur}

- W. Genschorek, Ferdinand S., ${ }^{7} 1987$

- C. Mörgeli, «Der S.-Skandal von 1915», in Schweiz. Rundschau für Medizin Praxis 77, 1988,

123-127

Autorin/Autor: Christoph Mörgeli

(c) 1998-2010 HLS: Alle Urheberrechte dieser elektronischen Publikation sind beim Historischen Lexikon der Schweiz, Bern. Für alle elektronisch publizierten Texte gelten dieselben Regeln wie für eine gedruckte Veröffentlichung. Nutzungsrechte und Zitierrichtlinien (PDF)

URL: http://www.hls-dhs-dss.ch/textes/d/D49487.php 